Studia UBB \$ligitalia, Volume 63 (LXIII) 2018, June, Issue 1, 55-68

Published Online: 2018-06-30

DOI:10.24193/subbdigitalia.2018.1.04

\title{
Digital and Coding Literacy for School Students
}

\author{
Mariana Dindelegan \\ Gheorghe Șincai High School, Cluj-Napoca
}

\begin{abstract}
In the digitalization era, the notion of gamification appeared in every field of activity. Experimenting gamification of programming hours by practitioners and teachers in the 2017-2018 school year at the 5th grade is part of the research area related to identifying ways to improve student engagement and skills for lifelong learning.

The article will present the outcome of this pilot experiment, which aims to track the evolution of pupils during the project, by analyzing and comparing the results from the initial evaluation with those from the final evaluation. The purpose of the article is, on one hand, to contribute to the literature with new results in the field of digitization of the teaching-learning activities through gamification, and, on the other hand, to present a new teaching instrument used to streamline the instructive-educational process at the fifth grade students, within the Computer Science, which is now a mandatory object. The experiment was conducted in accordance with the Creative Computing curriculum created by the ScratchEd team at the Harvard Graduate School of Education.
\end{abstract}

Keywords: digital literacy, coding literacy, programming, gamification, Scratch.

In the digitalization era, the notion of gamification appeared in every field of activity. Experimenting gamification of programming hours by practitioners and teachers in the 2017-2018 school year at the 5th grade is part of the research area related to identifying ways to improve student engagement and skills for lifelong learning. 
The article will present the outcome of this pilot experiment, which aims to track the evolution of pupils during the project, by analyzing and comparing the results from the initial evaluation with those from the final evaluation. The purpose of the article is, on one hand, to contribute to the literature with new results in the field of digitization of the teaching-learning activities through gamification, and, on the other hand, to present a new teaching instrument used to streamline the instructive-educational process at the fifth grade students, within the Computer Science, which is now a mandatory object. The experiment was conducted in accordance with the Creative Computing curriculum created by the ScratchEd team at the Harvard Graduate School of Education.

\section{Introduction}

Literacy is the ability to use a symbol system and a technological tool to comprehend, generate, communicate, and express ideas or thoughts by making a shareable product that others can interpret. This definition applies to both textual and coding literacy (Umaschi Bers, 2018).

Coding literacy is a requirement for participation in a digital world. This is because when we are not code literate, we must accept the devices and software we use with whatever limitations and agendas their creators have built into them. On the other hand, a code literate person stops accepting the applications and websites he uses at face value, and begins to engage critically and purposefully with them instead (Rushkoff, 2012).

Digital literacy consists of the skills, knowledge and understanding that enable critical, creative, discerning and safe practices with digital technologies. Moreover, it is about knowing when digital technologies are appropriate and helpful to the task at hand and when they are not (Digital literacy across the curriculum, 2011). The International Society for Technology in Education (ISTE) frames its benchmarks for digital literacy around six standards: creativity and innovation; communication and collaboration; research and information fluency; critical thinking, problem solving and decision making; digital citizenship and technology operations (ISTE, 2018). Thus, coding literacy could be regarded as being part of digital literacy.

In 2016, the study "Young Children (0-8) and Digital Technology. A qualitative exploratory study. National report: ROMANIA" was published. According to this study:

"Most of the children have basic operational skills (knowing how to open/shut down the device, how to connect to the internet, to install and delete apps, if they use a mobile device). When needing support, they usually ask one of the parents (not necessary the most skilled, but the nearest one), while few of them 
look for online support or ask their friends. In general, children at this age do not have a clear image of the online risks and do not take measures to protect their devices (this is sometimes done by the parent, or other skilled adult prompt by the parent) or to have a preventive behaviour online." (Velicu, 2016).

According to the study: "Romanians beyond display: attitude, behavior and habits of using the internet", carried out by the Romanian Institute for Evaluation and Strategy (RIES) between 4-16 May 2017, Romania is among the countries with the most advanced infrastructure of digital communications in the world. Despite this, the country does not excel in the share of people using technology, nor is it digitally literate at a high level. However, the digital generation is strong behind: $97 \%$ of young people aged between 12 and 18 say they use the internet. The study was conducted on a sample of 4,328 people aged over 12 years from Romania (Dancu, 2018). It is therefore necessary that these concepts of digital and coding literacy are introduced into schools as early as possible. Thus, they will be naturally assimilated by children who will live in a highly digitized world. Within this context, this study aims to present an overview of the level of digital literacy in primary school children, also trying to identify / determine the degree of acceptance of new technology by parents and children. Specific, it is intended to present the children and, indirectly, the adult population perception, the importance of early access to technology and therefore of introducing it as a subject in the primary school. This study is structured in two major parts: literature review of digital and coding literacy, and the presentation of the study from methodology to the obtained results.

\section{Literature review}

Education has always been subject to adopt the latest technology in order to be improved, made more accessible or meet as many needs as possible. In this context I went through the literature of Play-based digital learning (PBDL). The paper "Introducing the 'new' digital literacy of coding in the early years" (Claire Campbell and Chris Walsh, 2017) outlines the importance of PBDL in childhood. Here are mentioned two fundamentals of this approach:

"Children have the right to relax and play, and to join in a wide range of cultural, artistic and other recreational activities" (Article 31 of the United Nations Convention on the Rights of the Child, 1989).

Competence in coding is a practice that leads to digital literacy. 
In the book "Play in the Early Years" (Marilyn Fleer, 2013) it is demonstrated that students can learn coding and robotics through playful, practical, engaged and interactive learning experiences. It is necessary to introduce coding and robotics into school curriculum, but to use methods appropriate to the needs of young children. The methods have to include a balance between the learning experiences initiated by children and those initiated by teachers, according to "Early Years Learning Framework" (EYLF) (Commonwealth of Australia, 2009). Also, students should be seen as being able to learn using technology, while play and collaboration should be understood as innovative when integrating digital tools and technologies to stimulate children's curiosity (Dietze \& Kashin, 2013; Bølgan, 2012; Szmodis \& Columba, 2013).

From another perspective, there are works in literature to demonstrate that early introduction to PBDL is not necessary (Siegel, 2006; Bearne, 2009; Bazalgette \& Buckingham, 2013). They are offering class examples that highlight the particularities of multimodal interaction of children with moving image environments, and consider that those elements destabilize rather than consolidate. The authors conclude that the early introduction of coding has negative effects in the long-term assimilation process of both the binary and the non-binary, and suggest that the introduction of high-quality digitization into secondary and higher education is more beneficial.

Literature on PBDL abounds in results of practical experiments, those being generally implemented by businesses and educators. Notable results on which we conducted this paper are presented in several studies (Kwok, 2017; Prozesky \& Cifuentes, 2014). In "Starting from Scratch: Using Scratch as a Montessori Material to Develop Digital Literacy", Simon Kwok studied how Scratch programming language would help students develop digital literacy into the Montessori environment. The data collected showed that Scratch not only enabled students to develop digital literacy based on ISTE's achievement indicators (2016), but also met the general criteria outlined by Prozesky and Cifuentes (2014) for a technology to be integrated into the Montessori environment. The author used the ten principles of teaching and learning for technology integration in the Montessori classroom to argue how Scratch can be considered a Montessori material. These principles had been enunciated by Prozesky and Cifuentes (2014) and they are: engaging the senses, control of error, collaboration, isolation of concept, sequencing concrete to abstract, rewards and competition, peace, planes of development, creativity and imagination, concentration. The author showed that these things can be achieved using Scratch programming teaching programming skills, and that it would be an effective way to develop digital literacy to Montessori students (Kwok, 2017). 
(McDougall, J., Readman, M. and Wilkinson, P.) describes a research facilitated by a multinational technology provider, converging tablets used across school and home, a technology enhanced community 'third space' providing workshops for students aged 6-9 with their tutors from an Academy School on the south coast of England. The project aimed at creating a digital space for workshops (workshops being seen as a means of building relations, allowing tutors, parents and children to find cognition through socializing). The project demonstrated that traditional space, technology and parent-child-teacher socialization are beneficial to the introduction of modern learning tools that allow choosing the pedagogical method appropriate to each child. It has also been showed that it is necessary to create a space in which the familiar environment meets with the school one, in order to introduce PBDP. In our opinion, this project validates the theory of Icek Ajzen (2006) according to which the teacher needs to know the environment the child comes from in order to develop pedagogical methods in accordance with the child's behavior. Pedagogical materials built on this theory increase the child's engagement and desire to learn, regardless of the area under consideration. In projects within the PBDL area, we consider this aspect to be mandatory, bringing added value to the whole process of digitization.

In most of the studies conducted after 2009, there are arguments about the potential benefits of PBDL for early learners in terms of developing in them the so-called 21st century skills: problem-solving, exploration, skills acquisition, collaborative learning, social interaction and meaning generativity, as well as multisemiosis and criticality. These studies conclude that the benefits for children are of particular importance. (Lankshear and Knobel, 2003) demonstrate that these children are in fact "disadvantaged", namely: of diverse or multiple linguistic, socio-economic, race-ethnic backgrounds and diverse ability levels.

Our research also relied on the review of literature "Library preschool story times: Developing early literacy skills in children" (Maclean, 2008). This article shows that there is evidence to support that meaningful literacy activities, such as reading, singing and playing with children, can impact a child's brain development and subsequently help provide them with the pre-reading skills they need to start school. Neuroscientists tell us (Howard, 2013) that the type of learning based on technology that occurs in institutions such as libraries and museums is self-directed, experiential, content-rich and promotes executive function skills that can shape a child's success in school and life. Based on these results, we have built this experiment to find out how children from a developing country can access digital education and cope with the new digital age, regardless of their social background or material situation. 
The resulting theories can be reunited to create a powerful tool, useful in developing a holistic framework to streamline the introduction of PBDL in the curriculum. All this will allow the teaching-learning process to adapt to Web 2.0, Web 3.0 and, why not, Web 4.0 technologies. In this context, we focused on determining how prepared are Romanian children to have PBDL implemented in their learning-evaluation process.

\section{Material and method}

\subsection{Description of the experiment}

During the 2017-2018 school year, the "Dalia's Book" Association carried out the second edition of the project "Adopt a School!". Two IT companies were involved in the project to form and develop digital skills at primary level in 5 cities in the country. In this project, the volunteers from the involved companies carried out activities of teaching-learning-evaluation programming concepts through the Scratch application. The program followed the Creative Computing curriculum created by the ScratchEd team at the Harvard Graduate School of Education. The approach aims at involving technology in the educational process of children, providing them with the necessary support to carry out their studies and to achieve school performance in the digital age. The project wants to encourage learning by using the opportunities and tools that modern technology offers so that every child has access to digital education.

The didactic activity was considered as follows:

1. A group of 5 to 15 volunteers within a partner company organize the Scratch Club, with the help of a team lead and "Dalia's Book" Association.

2. Volunteers take part in a training session held by "Dalia's Book" Association to familiarize with the Scratch language and prepare to work with children.

3. The group organizes one-hour weekly meetings at the Scratch Club. The meetings take place in the school's computer lab throughout the second semester. The meetings are held by 5 volunteers, designated by turn.

4. Finally, we organize a Hackathon, where students create animations and games.

The primary education curriculum in Romania does not aim at developing digital skills. In this context, we started the current project to look at the effect of introducing digital competences in primary school. Lack of this dimension in the curriculum imposed as unique conditions in the choice of schools participating in the project the 
existence of a computer science lab in the school, and the availability of a fourth-grade teacher to participate with the class at the activities run by IT practitioners. The selected schools were situated nearby the companies participating in the project to ease volunteers participation in classes. Picked classes had an average of 30 pupils (between 24 and 36). The volunteers were IT company employees willing to introduce students to the digital world. Before starting classroom activities, they were taught pedagogy notions for primary classes and programming notions in Scratch. At the same time, the Creative Computing manual has been made available to them. The research is based on the structured interview method, using the questionnaire as a tool. The questionnaire was used to identify the 4th grader's profile before being subjected to a PBDL experiment. The observation method supports the idea that the familiar environment instills children to develop the primary digital competences required to enter the program. In this context, the study's hypothesis is that children of $Z$ generation have digital competences in their early years of study, more precisely they are digitally native.

Data processing was done using the software SPSS13 (Statistical Package for the Social Sciences) for Windows. The selected statistical methods are consistent with the theory and nature of the data processed, frequency assays and the Wilcoxon Signed Ranks Test for $p$-value $<0.05$.

Validation of the tool (the questionnaire) was based on the Reliability and Validity method. Following the test, we obtained that it is sensitive to the measured characteristics: alpha Cronbach $=0.756$, and the alpha value obtained is significant and suggests that the instrument is suitable for the purpose for which it was built. The study hypothesis is unilateral and according to the results of the analysis there are no differences between the study participants and the interaction effect with the instrument performed with Friedman's Chi-Square $=169,143$; $p$-value $=0.000$. So the differences between the items are generated by the answers given by the study participants, the test being able to differentiate students according to how they relate to technology.

\begin{tabular}{|l|l|}
\hline Item & Competence \\
\hline I use drawing software (eg Paint). & Information and media skills \\
\hline $\begin{array}{l}\text { I like to work in team. } \\
\text { I like the most in team work: .................. }\end{array}$ & $\begin{array}{l}\text { Responsibility and adaptability } \\
\text { Social responsibility } \\
\text { Collaborative and interpersonal skills }\end{array}$ \\
\hline
\end{tabular}




\begin{tabular}{|l|l|}
\hline Item & Competence \\
\hline $\begin{array}{l}\text { I manage documents and files (I create, save, } \\
\text { delete files and folders). }\end{array}$ & Information and media skills \\
\hline I place pictures, sounds, movies in documents. & Information and media skills \\
\hline I use the internet. & $\begin{array}{l}\text { Intellectual curiosity } \\
\text { Self-training }\end{array}$ \\
\hline I save pictures and sounds from the internet. & Information and media skills \\
\hline I use e-mail. & Communication skills \\
\hline I create animations. & Creativity and intellectual curiosity \\
\hline I manage CDs and flash memory on the computer. & Information and media skills \\
\hline I create games. & Creativity and coding literacy \\
\hline
\end{tabular}

In the study participated 119 pupils (59 male and 60 female participants) of seven educational units located in the cities of Cluj-Napoca, Timisoara, Bucharest, Brasov, Craiova and Sibiu in Romania. The questionnaire contained 10 items created to verify the digital competences of people who have expressed their willingness to take part in the study. The digital profile of future participants in the study is:

- $67.227 \%$ (80) confirmed that they use a drawing software while $32.773 \%$ (39) said they do not.

- $94.118 \%$ (112) confirmed that they like to work in a team while $5.882 \%$ (7) have a restraint from teamwork.

- $62.185 \%$ (74) confirmed that they know how to manage documents and files (create, save, delete files and folders) while $37.815 \%$ (45) said that they do not.

- $50.420 \%$ (60) confirmed that they can insert images, sounds, movies in documents, while $49.580 \%$ (59) do not know how.

- $100 \%$ (119) use the Internet for the following purposes, which are illustrated in the Figure 1:

- $46.218 \%$ (55) use the email while $53.782 \%$ (64) do not.

○ $64.706 \%$ (77) save multimedia files on the internet while $35.294 \%$ (42) do not.

○ $64.706 \%$ (77) use USB and CD while $35.294 \%$ (42) do not.

- $44.538 \%$ (53) create animations while $55.462 \%$ (66) do not.

- $28.571 \%$ (34) create games while $71.429 \%$ (85) do not.

○ $23.529 \%$ (28) have mobile phones while $76.471 \%(91)$ do not. 


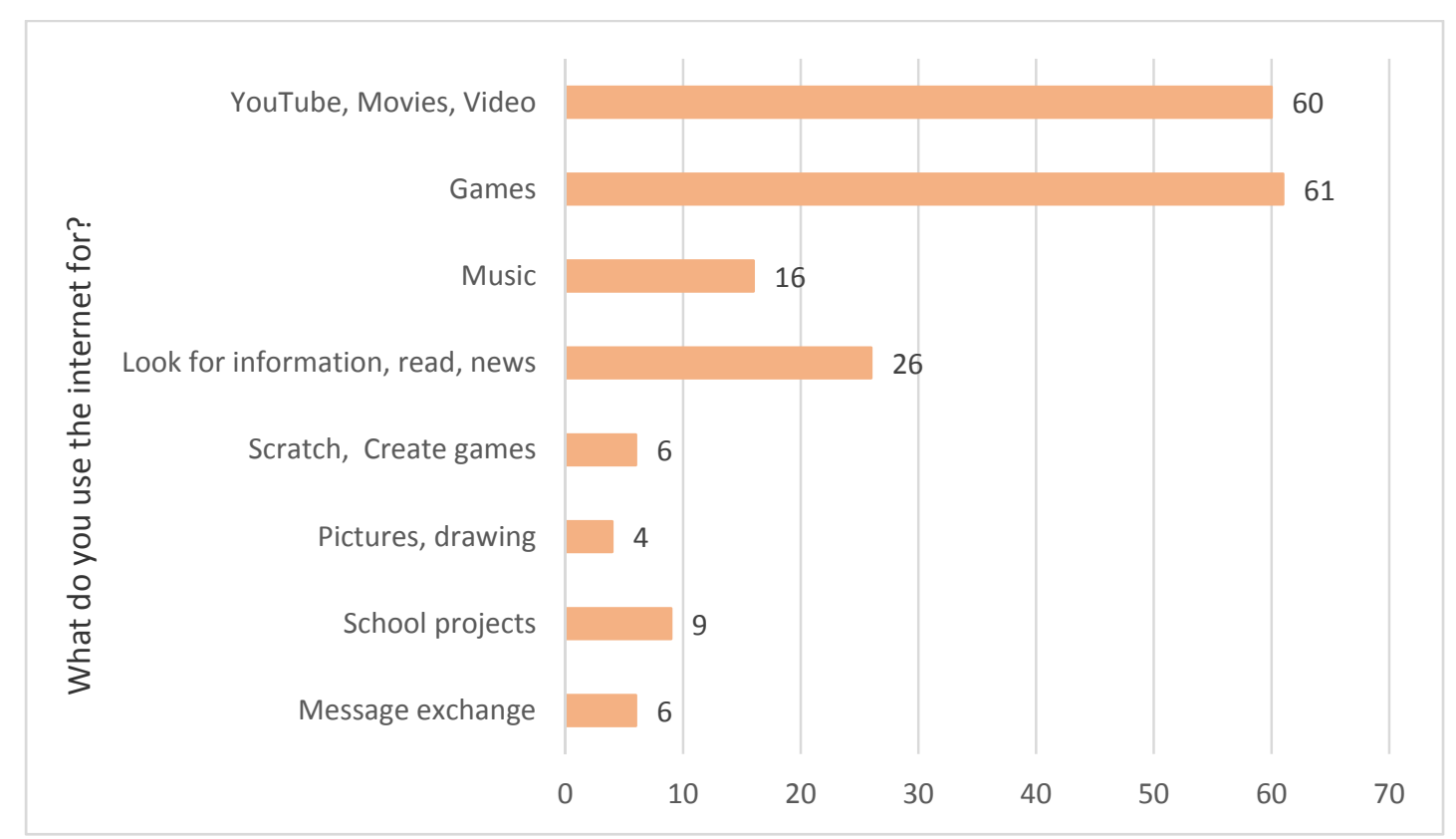

Figure 1. Purpose of using the internet

The study continued with the testing of statistical hypotheses. The research hypothesis is: there are differences between the digital abilities of the participants in the study. According to Shapiro-Wilks, data is not normally distributed, so the Wilcoxon Signed Ranks Test is applied and the following is obtained:

1. there are no gender differences in the use of drawing software $Z=-1,036, p-$ value $=0.3$;

2. gender does not influence the pleasure of working in a team $Z=-1.187, p=$ 0.235

3. gender does not influence the existence of knowledge of document and file management (create, save, delete files and folders) $Z=-1.247, p=0.213$;

4. gender does not influence the existence of knowledge about the use of documents and audio / video files in documents $Z=-0.273, p=0.785$;

5. gender does not influence the existence of knowledge of downloading audio / video documents and audio files from the internet $Z=-0.832, p=0.405$;

6. gender does not influence the existence of e-mail knowledge $Z=-1,929, p=$ 0.054

7. gender influences the existence of knowledge related to the creation of games $Z=-3.041, p=0.002$; more precisely, female gender has greater experience in creating games; this information is illustrated in the Figure 2; 


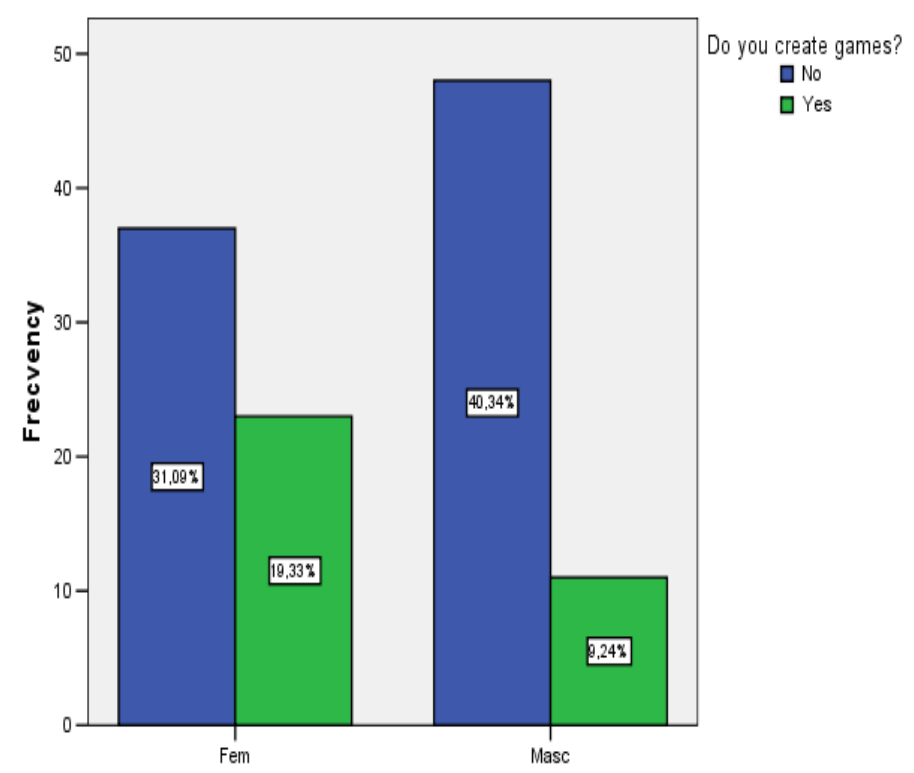

Figure 2. Creativity and coding literacy by gender

8. gender influences the existence of knowledge related to creation of animations $Z=-2.367, p=0.018$; more specifically, female gender has greater experience in creating animations and this is illustrated in the Figure 3.

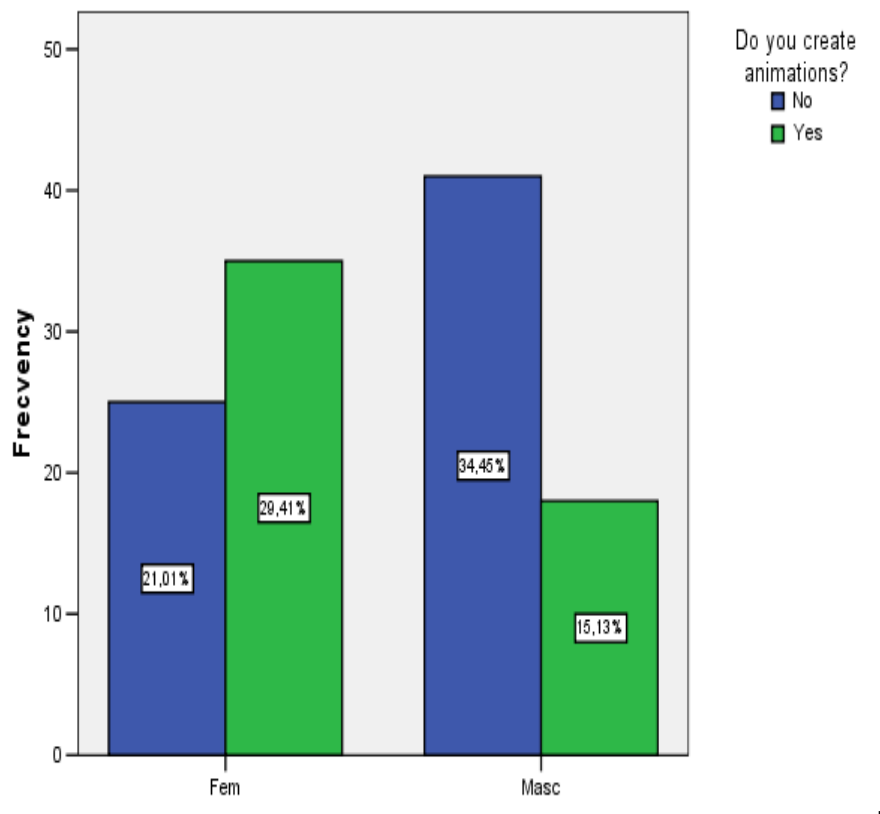

Figure 3. Creativity and intellectual curiosity by gender 
From our study results that females have the skills of creativity and intellectual curiosity, respectively, creativity and coding literacy more developed than males.

In this context, we continued the analysis using the TwoStep method to find the number of clusters that exist in a sum of different types of data. The null hypothesis of this stage is the following: there is no difference between the knowledge of the digital competences of the student groups. In order to validate / invalidate this hypothesis, we applied the cluster analysis based on the variables studied. The null hypothesis is rejected, and the result demonstrates that students are grouped into two clusters based on the attributes considered in the study. These groups are characterized by the fact that the value of inertia between classes significantly exceeds the values of inertia within the same class. Therefore, differences based on responses are in the following dimensions: Do you use drawing software? $(F=32.762$, $p$-value $=0,000)$; Do you work with documents and files (create, edit, delete)? $(F=50.509$, $p$-value $=0.000)$; Do you use images, audio or video in documents? $(F=102.464$, $p$-value $=0.000)$; Do you save images and audio files from the internet? $(F=22.618, p$-value $=0.000)$; Do you use email? $(F=37.547, p$-value $=0.000)$; Do you create animations? $(F=132.913 ; p$-value $=0.000)$; Do you use CDs and USB drives? $(F=8.582$; $p$-value $=0.004)$; Do you create games? $(F=83.321 ; p$-value $=0.000)$.

The result of the cluster analysis (K-means method) based on the studied variables demonstrates that the students are grouped as follows:

The first group of students - $53.782 \%$ comprises pupils whose responses determined they have responsibility and adaptability.

The second group of students $-46.218 \%$ comprises the students who, based on the answers, have established themselves as having creativity and intellectual curiosity, creativity and coding literacy, information and media skills.

The difference between the two groups is due to the fact that those who have creativity and intellectual curiosity, creativity and coding literacy, information and media skills have not developed social responsibility and adaptability. A direct justification is given by the fact that many children grow up in front of tablets and computers (parents being busy working) and do not have developed communication skills and a desire to work in a team. On the other hand, through games they develop creativity and intellectual curiosity, creativity and coding literacy, media skills and also have access to information.

In conclusion, the participants in the study have skills generated by having devices and Internet access since early-life. This facilitates the almost native development of digital age skills, namely: information and media skills, responsibility and adaptability, social responsibility, interpersonal collaboration skills, intellectual curiosity, self-communication, on-line communication skills, creativity, coding literacy, 
critical thinking and systemic thinking. Based on the study, we can say that a large number of children living in the big centers of Romania are digitally native, so assimilation of digital knowledge will not be a problem for them.

Based on the descriptive analysis made using the data collected through the questionnaire we validated the study hypothesis: more than half of the children participating in the study have digital competences at the beginning of the study. In addition, two clusters have been identified. The first cluster contains children who have the necessary skills to naturally use IT in learning, without traditional learning being a problem for them. On the other hand, the second group is more geared towards digitization, having potential difficulties in the traditional learning process. In this context, we can say that they will be able to successfully cope with a literacy program, developed accessible by the business community (non-pedagogues).

The results of our study support the results of research in the literature that digital literacy positively influences children's curiosity, problem solving, exploration, autonomy and the development of printed and non-printed skills. At the same time, digital literacy is expanding its awareness potential by increasig semiotic repertoire.

Similarly, we conducted a survey of the teachers involved in the project using the observation method. It highlighted the fact that they need mentoring to increase confidence in the importance of integrating digital technologies into educational programs for children. At the same time, the project demonstrates the need for a partnership based on professional respect between IT\&C and IT\&C pedagogues.

\section{Conclusion}

The dream of all teachers is to teach their students everything they know. They enter a classroom with the desire to succeed in this dream and often come out feeling disappointed and disillusioned. Pupils have different goals. Their interest in learning is somehow overshadowed by their desire to get a better grade, distraction from what is happening in their surroundings, and lack of direct involvement in classroom activities. Following the study, we found out that the participating students are not prepared to cope with PBDP in the same way. 53.782\% of them have the necessary skills to naturally use IT in learning, without traditional learning being a problem for them. On the other hand, $46.218 \%$ of them are more geared towards digitization, having potential difficulties in the traditional learning process.

Most of the teachers are comfortable with the traditional teaching style. However, studies (Greer and Heaney, 2004) have shown that this transfer of information does not remain in children's mind for a long time. Lecture type teaching 
is not an effective teaching method. Students should be actively involved in learning. The results of our study demonstrate that 4th grade children have all the necessary skills to participate in lessons where technology is involved. Thus, the lesson turns into an active learning space, the teacher-child relationship being one of collaboration. PBPD represents a simple way to introduce coding and robotics into the primary education. However, the process of introducing PBPD into the curriculum is slow. This is because the use of alternative teaching techniques depends on the size of the class, the availability of classrooms equipped with technology, the shyness of the students, the fear of being mistaken for colleagues, the lack of time, etc.

The general conclusion of the specialized literature derived from the definition of the PBPD concept is that the way of introducing this concept into primary education is possible, but through the game (McDonald, S., \& Howell, J., 2012). PBPD has a beneficial effect on the education and training of the child seen as an adult consumer of digital culture.

\section{Works Cited}

Bazalgette, C., \& Buckingham, D. (2013). Literacy, media and multimodality: A critical response. Literacy, 47(2), 95-102.

Bølgan, N. (2012). From IT to tablet: Current use and future needs in kindergartens. Nordic Journal of Digital Literacy, 7(3), 154-170.

Howard, M. L. (2013). Growing young minds: How museums and libraries create lifelong learners. Washington, DC: Institute of Museum and Library Services.

Bearne,E.(2009). Multimodality, literacy and texts: Developing a discourse. Journal of Early Childhood Literacy,9(2),156-187.

Dietze, B., \& Kashin, D. (2013). Shifting views: Exploring the potential for technology integration in early childhood education programs. Canadian Journal of Learning and Technology, 39(4), 1-13.

Maclean, J. (2008). Library preschool storytimes: Developing early literacy skills in children. Library Preschool Storytimes. Retrieved from https://ed.psu.edu/goodling-institute/judy-maclean-library-preschool-storytimes

McDonald, S., \& Howell, J. (2012). Watching, creating and achieving: Creative technologies as a conduit for learning in the early years. British Journal of Educational Technology, 43, 641-651. doi: 10.1111/j.1467-8535.2011.01231.x 
McDougall, J. (2010). A crisis of professional identity: How primary teachers are coming to terms with changing views of literacy. Teaching and Teacher Education, 26, 679-687.

Campbell Claire, Walsh Chris (2017) Introducing the 'new' digital literacy of coding in the early years. Practical Literacy, 22 (3). pp. 10-12.

Fleer, M. (2013). Play in the early years. Port Melbourne, VIC: Cambridge.

Commonwealth of Australia. (2009). Belonging, Being, Becoming: The Early Years Framework for Australia. Canberra: Australian Government Department of Education, Employment and Workplace Relations for the Council of Australian Government. Retrieved from http://foi.deewr.gov.au/system/files/doc/other/belonging_being_and_becoming_ the_early_years_lerning_framework_for_australia.pdf

Lankshear, C. \& Knobel, M. (2003). New technologies in early childhood literacy research: A reviewofresearch. JournalofEarlyChildhood Literacy, 3(1),59-82.

Siegel,M.(2006).Rereading the Signs: Multimodal Transformations in the Field of Literacy Education, Language Arts,84(1),65-77.

Siegel, M., Kontovourki, S., Schmier, S., \& Enriquez, G. (2008). Literacy in motion: A case study of a shape-shifting kindergartener. Language Arts, 86(2), 89-98.

Szmodis, W., \& Columba, L. (2013). Technology for young learners: Making a case for innovative tools. National Teacher Education Journal, 6(1), 61-68.

Greer, L., and Heaney, P. J., 2004, Real-Time Analysis of Student Comprehension: An Assessment of Electronic Student Response Technology in an Introductory Earth Science Course: Journal of Geoscience Education, v. 52, p. 345-351.

McDonald, S., \& Howell, J. (2012). Watching, creating and achieving: creative technologies as a conduit for learning in the early years. British Journal of Educational Technology, $43,641-651$

McDougall, J. (2010). A crisis of professional identity: How primary teachers are coming to terms with changing views of literacy. Teaching and Teacher Education, 26, 679687 